\title{
Lingual Metastasis to the Tip of the Tongue as the First Sign of Metastatic Spread in Lung Cancer: A Case Report and Review of the Literature
}

\author{
So-Yoon Lee, Mi Kyung Kim, and Cheong Se Won \\ Department of Otorhinolaryngology-Head and Neck Surgery, CHA University, Bundang CHA Medical Center, Seongnam, Korea
}

\author{
이소윤 · 김미경 · 원청세 \\ 차의과학대학교 분당차병원 이비인후과-두경부외과학교실
}

설첨부의 전이성 설암을 첫 증상으로 발견한 폐암: 증례보고 및 문헌고찰

\author{
Received January 12, 2017 \\ Revised February 15, 2017 \\ Accepted March 6, 2017 \\ Address for correspondence \\ So-Yoon Lee, MD \\ Department of Otorhinolaryngology- \\ Head and Neck Surgery, \\ CHA University, \\ Bundang CHA Medical Center, \\ 11 Yatap-ro 65beon-gil, Bundang-gu, \\ Seongnam 13496, Korea \\ Tel $+82-31-780-5344$ \\ Fax $+82-31-780-5347$ \\ E-mail entlsy27@cha.ac.kr
}

Lingual metastasis is defined as the metastasis of malignant tumors to the tongue from another primary organ cancer. Primary lung cancer which had metastasized to the tongue was reported in $0.2-1.6 \%$ of these cases. The base of the tongue is the most frequent site of lingual metastasis due to its rich vascular supply and relative lack of mobility compared with other areas of the tongue. The aim of this article is to report a benign appearing lingual metastasis to the tip of the tongue as the first sign of metastasis from squamous cell carcinoma of the lung. Clinical presentation of lingual metastasis resembled a hyperplastic or reactive lesion, such as a pyogenic granuloma or submucosal mass. In cases where there was a single metastatic focus, a surgical excision was recommended as a palliative measure for pain control, the prevention of infection or bleeding, and the maintenance of an acceptable oral function.

Korean J Otorhinolaryngol-Head Neck Surg 2018;61(9):489-91

Key Words Lingual metastasis · Lung cancer · Tongue.

\section{Introduction}

Metastatic tumors of the oral cavity are uncommon, representing approximately $0.3 \%$ of all oral malignant tumors. ${ }^{1)}$ The gingiva is the most common metastatic site in the oral cavity, followed by the base of the tongue. ${ }^{1,2)}$ Common primary sites that result in lingual metastases include the lungs in men and the breasts in women. ${ }^{3)}$ Primary lung cancer which had metastasized to the tongue was reported in $0.2 \%$ to $1.6 \%$ of cases. ${ }^{4}$ Patients with lingual metastasis typically have additional widespread metastases, and thus a poor prognosis. ${ }^{5)}$ In the present study, we describe a rare case of lingual

This is an Open Access article distributed under the terms of the Creative Commons Attribution Non-Commercial License (https://creativecommons.org/licenses/by-nc/4.0) which permits unrestricted non-commercial use, distribution, and reproduction in any medium, provided the original work is properly cited. metastasis to the tip of the tongue from primary lung squamous cell carcinoma (SCC) as the first sign of metastasis without widespread metastasis to the other solid organs.

\section{Case}

A 63-year-old man was referred with a 2-week history of a mass on the tip of the tongue. He had a history of heavy alcohol and tobacco use. On physical examination, a demarcated, fungating and rubbery mass measuring $1.5 \times 1.0 \mathrm{~cm}$ was seen on the tip of the tongue (Fig. 1). The patient reported interrupted mastication and mild pain. An excisional biopsy with LASER and subsequent primary repair was done. The $1.5 \times 1.0 \mathrm{~cm}$ mass was completely excised with $2 \mathrm{~mm}$ margins, and appeared to be encapsulated and well demarcated 
from the tongue muscle without evidence of invasion. On histopathology, moderately differentiated SCC was reported,

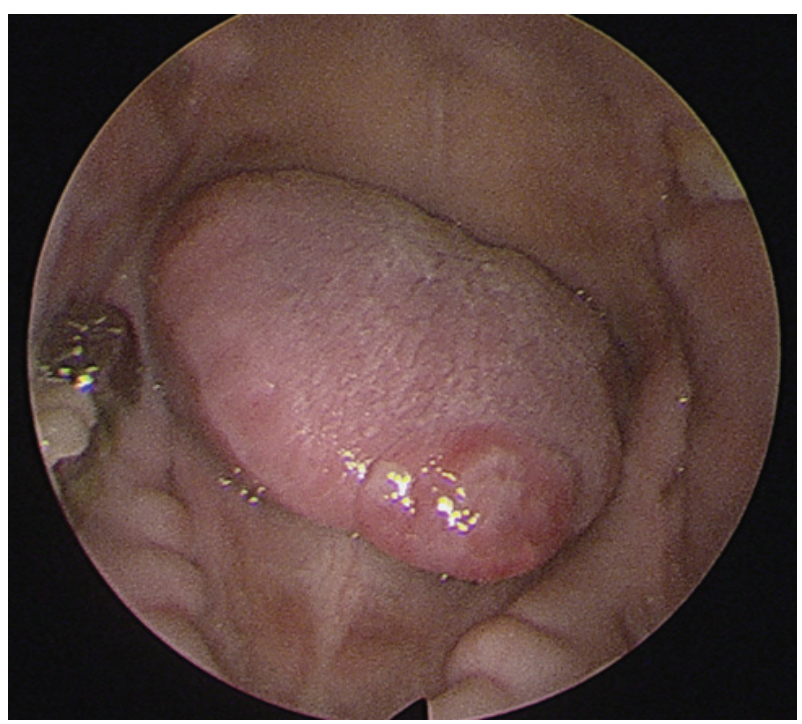

Fig. 1. Physical examination findings. A benign appearing, well-demarcated, fungating, and rubbery mass measuring $1.5 \times 1.0 \mathrm{~cm}$ was identified on the tip of the tongue. and it was suspected to be metastatic rather than a primary lesion. Tumor cells were found beneath the normal squamous epithelium of the tongue without dysplasia (Fig. 2A), thus sparing the tongue mucosa. Additionally, numerous SCC tumor cells were found in the lymphatic vessels, which was further evidence of lymphatic metastasis (Fig. 2B). The margins were negative for malignancy. Whole body positron electron tomography-computed tomography was then performed and it represented with strong FDG uptake in the right lung (max-SUV=32.6) and in the mediastinal (max-SUV=16.7), sub-diaphragmatic (max-SUV=4.9), aorto-caval, para-aortic, and supraclavicular lymph nodes (max-SUV=4.6). There was no evidence of distant metastasis to the other solid organs (Fig. 3). Percutaneous needle aspiration from the lung lesion was performed and the diagnosis was SCC, moderate differenciated. Pathologic diagnosis of the lung was matched for the result of the tongue lesion and it represented that the lung was the primary site. The final diagnosis was the lung SCC with lingual metastasis (AJCC stage IV; T3, N3, M1),

Fig. 2. Histopathology of the tongue mass. Squamous cell carcinoma (SCC, asterisk) was identified beneath the normal epithelium of the tongue ( $\mathrm{H} \& \mathrm{E}$ stain, original magnification $\times 20$ ) (A). No dysplasia or SCC in situ was identified in the area between the normal epithelium of the tongue and the SCC cells (arrow). Numerous squamous cell tumorlets were found in the lymphatic vessels (asterisk) (H\&E stain, original magnification $\times 400)(B)$.
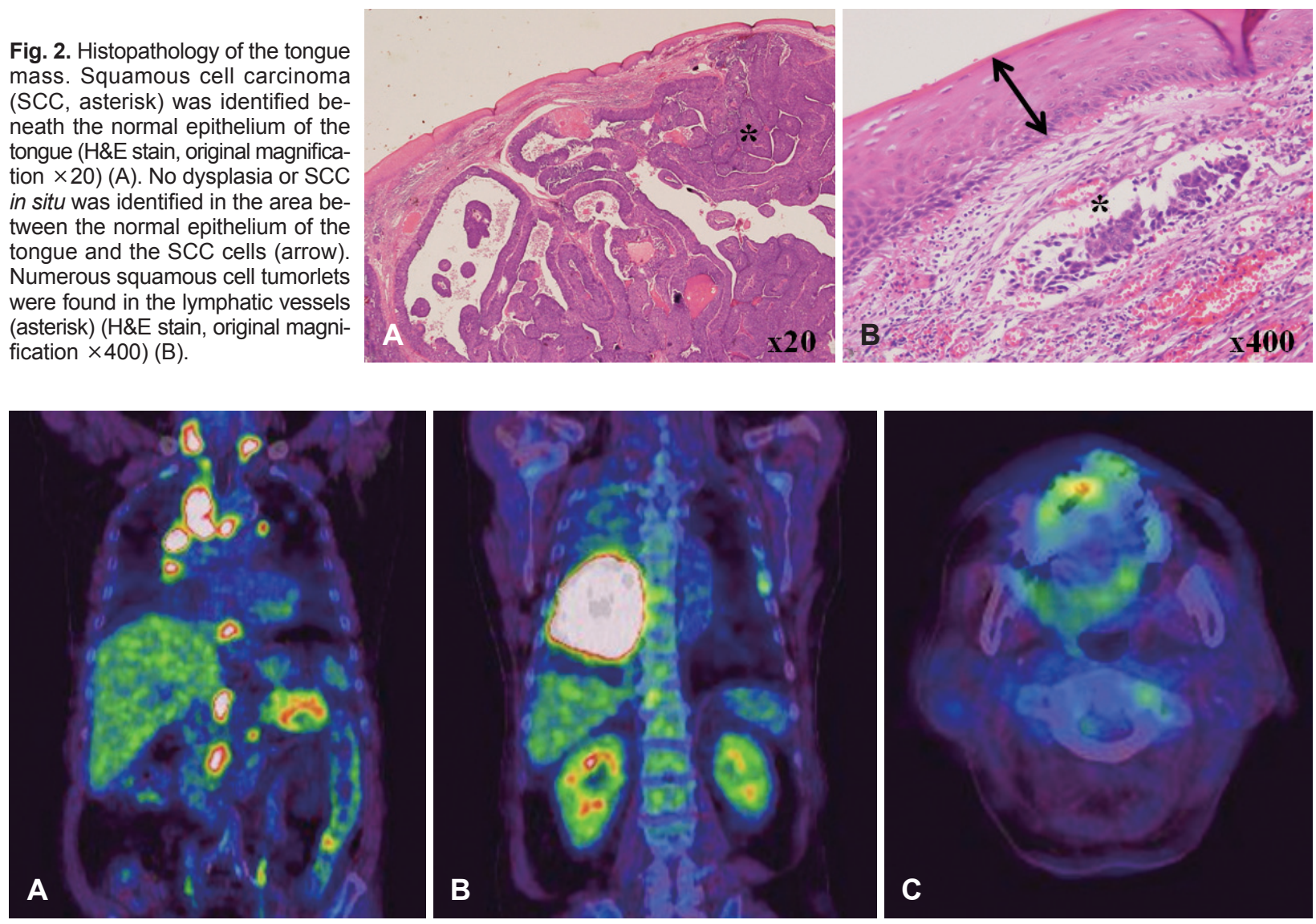

Fig. 3. PET-CT imaging. Coronal view: increased FDG uptake was identified in the lower lobe of the right lung (max-SUV=32.6), and in the mediastinal (max-SUV=16.7), sub-diaphragmatic (max-SUV=4.9), aorto-caval, para-aortic, and supraclavicular lymph nodes (maxSUV=4.6) without evidence of other solid organ involvement (A and B). Axial view: increased FDG uptake was identified in anterior tongue (max-SUV=3.7) (C). PET-CT: positron electron tomography-computed tomography. 
and the patient was treated with gentamicin and cisplatinbased chemotherapy. After excision of the mass, the wound on the tip of the tongue healed well and the patient's symptoms of difficulty with swallowing and mastication resolved. The patient was followed up for 8 month and died of the disease.

\section{Discussion}

The oral cavity is an uncommon site for metastatic tumor cell colonization and is usually indicative of widespread disease. Zegarelli, et al. ${ }^{5)}$ reported 12 cases of lingual metastases in the autopsy specimens of 5933 patients with various malignancies, and only two cases were found in 579 patients with primary lung cancer. The gingiva was the most common metastatic site in the oral cavity, followed by the tongue. ${ }^{6)}$ To date, 31 lingual metastases from lung cancer (9 adenocarcinomas, 8 mesotheliomas, 4 small cell carcinomas, 3 large cell carcinomas, 2 sarcomas, 2 fibrous histiocytomas, and 3 SCCs) have been reported in the literature. ${ }^{4-7)}$ Clinical presentation of malignant metastasis to the oral mucosa resembled a hyperplastic or reactive lesion, such as a pyogenic granuloma or submucosal mass. Lingual metastases typically located at the base or dorsolateral border of the tongue due to the rich vascular supply of lymphatics and blood. ${ }^{2)}$ Metastases to the tip of the tongue, however, have never been reported. Metastasis of various cancers to distant organs is not a random event; rather it is a regulated and site-specific process. ${ }^{8)}$ The possible routes of metastasis to the tongue include systemic, venous, and lymphatic circulation. Tumors in the lung can gain access to the pulmonary veins which drain into the left side of the heart, subsequently entering systemic circulation where the cells may metastasize to any organ in the body. ${ }^{5)}$ Batson ${ }^{9)}$ proposed the valveless vertebral venous plexus as a mechanism for bypassing filtration through the lungs, which could account for the increased distribution of axial skeleton and head and neck metastases. Differentiating primary intraoral malignancy from a metastatic tumor is challenging and the histologic diagnosis is vital. Metastatic tumors in the tongue are usually located beneath the normal surface epithelium, which is not suggestive of SCC in situ. ${ }^{4,6)}$ In the present case, dysplasia of the normal epithelium was not found, and numerous tumorlets were identified in the lymphatic vessels. And on imag- ing studies, there was no metastatic lymphadenopathy in the upper neck levels. In this case, sparing of the tongue mucosa and lack of lymphatic metastasis to the first echelon drainage region from the tongue allowed us to make the diagnosis of lingual metastasis. Also, histopathologic diagnosis proved that lung SCC was the primary site and it correlated to the metastatic pathology in this case.

Treatments of lingual metastasis aiming to improve symptoms include local resection, radiotherapy, or chemotherapy. In cases in which there is a single metastatic focus, surgical excision may be performed as a palliative measure for pain control, prevention of infection or bleeding, and maintenance of an acceptable level of oral function. ${ }^{7)}$ In one study in which the oral tumor was the only metastatic lesion, resection seemed to improve the prognosis of several patients, although the follow-up period was relatively short. ${ }^{10)}$ The prognosis of patients with lingual metastases is generally poor, since most already have widespread disease. In a previous study, 9 of 12 patients with lingual metastases had wide spread metastases with more than eleven organs involved. ${ }^{5)}$ Mean survival after diagnosis of lingual metastasis from lung cancer is approximately 10.6 months (range, 3 days -8 years). ${ }^{4,5,7)}$

\section{REFERENCES}

1) Hirshberg A, Leibovich P, Buchner A. Metastases to the oral mucosa: analysis of 157 cases. J Oral Pathol Med 1993;22(9):385-90.

2) Yoshitomi I, Kawasaki G, Mizuno A, Nishikido M, Hayashi T, Fujita $\mathrm{S}$, et al. Lingual metastasis as an initial presentation of renal cell carcinoma. Med Oncol 2011;28(4):1389-94.

3) Marioni G, Gaio E, Poletti A, Derosas F, Staffieri A. Uncommon metastatic site of renal adenocarcinoma: the oral tongue. Acta Otolaryngol 2004;124(2):197-201.

4) Terashima T, Matsuzaki T, Kawada I, Nishida J, Tanaka Y, Morishita $\mathrm{T}$, et al. Tongue metastasis as an initial presentation of a lung cancer. Intern Med 2004;43(8):727-30.

5) Zegarelli DJ, Tsukada Y, Pickren JW, Greene GW Jr. Metastatic tumor to the tongue. Report of twelve cases. Oral Surg Oral Med Oral Pathol 1973;35(2):202-11.

6) Hirshberg A, Shnaiderman-Shapiro A, Kaplan I, Berger R. Metastatic tumours to the oral cavity-pathogenesis and analysis of 673 cases. Oral Oncol 2008;44(8):743-52.

7) Tanaka N, Hidaka S, Yamamura M, Ohyama H, Urade M. Metastatic cutaneous carcinosarcoma to the tongue. Int J Oral Maxillofac Surg 2010;39(10):1033-6.

8) Pantel K, Brakenhoff RH. Dissecting the metastatic cascade. Nat Rev Cancer 2004;4(6):448-56.

9) Batson OV. The function of the vertebral veins and their role in the spread of metastases. Ann Surg 1940;112(1):138-49.

10) Nakamura T, Ishimaru J, Mizui T, Kobayashi A, Toida M, Makita H, et al. Osteosarcoma metastatic to the mandible: a case report. Oral Surg Oral Med Oral Pathol Oral Radiol Endod 2001;91(4):452-4. 